\title{
Towards a Conceptualization of Legal English as a Lingua Franca?
}

\author{
Patrizia Anesa ${ }^{1}$ \\ ${ }^{1}$ Department of Foreign Languages, Literatures and Cultures, University of Bergamo, Italy \\ Correspondence: Patrizia Anesa, Room 206, University of Bergamo, Piazza Rosate 2, Bergamo 24129, Italy. \\ E-mail: patrizia.anesa@unibg.it
}

$\begin{aligned} & \text { Received: January 28, } 2019 \\ & \text { Accepted: March 25, } 2019 \quad \text { Online Published: October 13, } 2019 \\ & \text { doi:10.5539/ijel.v9n6p14 }\end{aligned} \quad$ URL: https://doi.org/10.5539/ijel.v9n6p14

\begin{abstract}
English is de facto reinforcing its role as the language of international legal communication. Indeed, while different national languages continue to play a crucial role in the definition, the execution, and the application of the law, English is increasingly employed by non-native legal professionals worldwide. Thus, this study focuses on the use of English as a Lingua Franca (ELF) in legal settings and aims to offer considerations towards the conceptualization of Legal English as a Lingua Franca (LELF).

As English is considered a global asset in legal communication, it is argued that a finer problematization of LELF is imperative. In this respect, the study also discusses whether it is possible to apply the concept of a lingua franca to legal language tout court or whether the distinctive features of legal discourse across systems make the definition of LELF inapplicable from a conceptual perspective.

This article also offers a reflection on the main concerns which arise regarding the widespread use of English in legal settings, especially in the light of the specificities of different legal systems, legal cultures and communities of practice. Thus, all stakeholders involved should adopt a more reflexive approach in order to go beyond the unproblematic acceptance of LELF across legal settings and to be more aware of the implications and consequences that its usage entails.
\end{abstract}

Keywords: ELF, legal English, legal English as a Lingua Franca, English for legal purposes, legal communication

\section{Introduction}

The rapid growth in international contact has led to the need for a global language in a wide range of professional fields. In this regard, English has become de facto the language of choice for a significant number of people operating in the sphere of law, for instance (although clearly not exclusively) when dealing with international disputes. The use of a common language is also deemed necessary in several communicative situations not only in order to allow for the transmission of specific information but also, more broadly, to promote the exchange of ideas and reflections among legal professionals with different linguistic backgrounds.

Unsurprisingly, the use of English as an international language in different professional settings has received considerable scholarly attention. A clear example is represented by business communication, to the extent that the concept of Business English as a Lingua Franca (BELF) is now well-established and has been investigated thoroughly from multiple perspectives. This is demonstrated by several studies such as those by Cogo (2016b), Cogo and Yanaprasart (2018), Ehrenreich (2016), and Gerritsen and Nickerson (2009).

In the area of legal communication, English has been described as "the lingua franca of lawyers" (e.g., Orts Llopis, 2009), "a lingua franca for law" (Orts Llopis, 2015), or the European lingua franca in legal settings (Campos, 2010). However, a formal conceptualization of Legal English as a Lingua Franca (LELF) is still in an embryonic phase. Moreover, the discussion of the rift emerging between legal professionals belonging to different cultures, when engaging in interaction, has often been merely of an anecdotal nature and thus needs more in-depth investigation.

The first section of this paper tackles the notions of legal convergence and language convergence. Section Two describes the role of English as the language of international legal communication and, more specifically, attempts to offer a preliminary conceptualization of LELF. Subsequently, reflections are offered on the risks, concerns, and affordances which are related to LELF. 
This study is designed to provide an account of the contexts in which Legal English is employed as a lingua franca. It also seeks to provide insights which can be used for the developments of materials for Legal English pedagogy and training. The paper is mainly theoretical in its nature, although it draws significantly on previous empirical research. Instead of attempting to impose the acceptance of the concept of LELF, it aims to problematize its very conceptualization, to gain finer insights into a current phenomenon which deserves focused attention given its ample spectrum of application.

\section{Legal Convergence as Language Convergence?}

Some could argue that the specificities of each legal system mean it is not possible to offer an exhaustive description of LELF as an international language. Indeed, the profound variances which characterize different legal cultures may impede the acceptance of a single language serving as a common denominator. Moreover, it is also evident that, despite the partial dismantling of international boundaries which has taken place globally, especially from an economic perspective, legal frameworks across the world continue to be characterized by considerable differences. From this perspective, for instance, the implementation of legislation depends on the distinctive traits of each country, and specifically that country's legal tradition, social practices, culture, and values (Bhatia, Engberg, Gotti, \& Heller, 2005).

However, the majority of international transactions are carried out in English, and related legal procedures and practices have long been based on the use of English worldwide (Vogt, 2004). Thus, the differences between systems make the use of a common language a necessity, rather than a chimera, and, consequently, a fascinating topic for investigation. What is more, at least in Europe, the two main legal traditions of Civil Law and Common Law are gradually converging (Orts Llopis, 2009; for a discussion of the distinction between the two systems, and its partial and relative nature, see Bohlander, 2014). In this respect, the use of LELF may be seen as both a cause and a consequence of this process, determined primarily by the need for mutual understanding and the integration of common practices and procedures.

Lierman (2013) defines the law as a "complex adaptive system" because it consists of a multitude of interconnected elements and has the capacity to adapt according to the changing environment. He also emphasizes that "the equilibrium between the concurring legal systems is to a certain extent restored by convergence: convergence of methods of interpretation, of legal instruments and legal principles beyond the limits of separate branches of law and legal orders" (2013, p. 15). The convergence of legal cultures at an international level is essential in a globalized world. In particular, as law plays a crucial role in economic integration, the differences in legal systems are a key determinant in the increase of transaction costs in international trade; consequently, "the process of globalization naturally seems to call for increasing standardization of the law" (Crettez, Deffains, \& Musy, 2013, p. 346). Thus, legal convergence may be described as a trend moving towards the implementation of uniform legal responses to the same legal issues across boundaries, through cooperative processes such as legal harmonization or legal unification (e.g., Boele-Woelki, 2010). However, it should be pointed out that the notion of legal convergence has also received considerable criticism, for instance with regards to the lack of appropriateness, comprehensiveness, and clarity of regulations introduced through legal harmonization (Higgs, 2000). In other words, to some extent there exists a growing need for convergence in terms of legal culture, but its actual realization may be in contrast to the necessity of preserving a more endogenous approach.

From another perspective, we can also talk about the need for convergence in terms of legal language. This form of convergence is intended as the growing use of a common language which complements, rather than replaces, national languages. Indeed, the constant increase in the use of English in international legal contexts does not imply that English may substitute national languages, which are the fundamental tool through which national legislation is enacted, but simply that the existence of LELF is a reality, and one that is likely here to stay given the growing use of English in international legal communication.

\section{English as the Language of International Legal Communication}

\subsection{Conceptualizing LELF}

LELF can be intended as the particular use of ELF in legal settings. It is conceived here as having its own distinct ontology (which presents similarities, but also variations, with reference to ELF at large or to Legal English) and hence deserving of linguistic and pragmatic research.

Variability and contextuality are fundamental elements of ELF (Seidlhofer, 2011), and, consequently, of LELF. Hence, any attempt to conceptualize LELF inevitably leads to complex theoretical considerations rather than to one straightforwardly defined formulation. Research on legal discourse and ELF should be seen as informing 
one another, rather than as isolated entities. Moreover, the concept of LELF, if accepted, should be intended as a multilingual and multicultural phenomenon, and not simply as a specific form of English. Indeed, the multilingual paradigmatic reorientation has led to an epistemic shift towards the conceptualization of ELF discourse as multilingual or translingual practices (Canagarajah, 2013; Jenkins, 2015; Ortega, 2013, p. 48). Accordingly, LELF should be observed neither from a deficit perspective in relation to a (rather artificial) abstract conceptualization of legal English nor from an additive viewpoint (i.e., as the mere addition of the specifies of the different legal languages synthesized in LELF). Rather, it is a transformative phenomenon, involving new, expanding, and evolving repertoires (cf. Cogo, 2016a, on "translanguaging" in ELF), which are not just linguistic, but also of a socio-cultural and disciplinary nature.

The contexts of usage of LELF are very heterogenous, in terms of users, settings, and forms. LELF is obviously employed in those settings and institutions, such as international courts and international bodies, where English is a working or an official language (e.g., the UN or the WTO). In effect, English is also employed widely in both international and EU law. In particular, in the field of international criminal law, the creation of ad hoc tribunals, such as the International Criminal Tribunal for the former Yugoslavia or the International Criminal Tribunal for Rwanda, as well as courts such as the International Criminal Court (ICC), constitutes an example of the affirmation of English in the field.

However, the presence of English goes far beyond these spaces. For instance, Contract Law and Business Law make wide use of it, and contracts and agreements of different types (e.g., employment agreements, sales agreements, non-disclosure agreements, etc.) are often produced in, or translated into, English. Moreover, alternative dispute resolution forms such as arbitration, mediation, and conciliation are frequently conducted in English in international contexts, regardless of the nationalities of the parties involved and the native language of the arbitrators, mediators, or conciliators. In essence, English is adopted daily as a lingua franca by professionals operating in the legal field across different genres. Hence, English may also be employed in lawyer-client communication, in meetings, at international conferences and seminars, online (e.g., legal forums and legal blogs), in training, and in scholarly texts, to name but a few.

The widespread use of English may be seen, on the one hand, as the epitomization of the power of the legal cultures of Anglophone countries, especially the US and the UK. On the other hand, it may also be interpreted as a means which allows different legal cultures to communicate, in line with the process which Frade (2007) calls "legal globalization" and which inevitably entails the need for a shared tool of communication. In other words, the specificity of the legal system in each country may appear to impede a linguistic colonialism on the part of English (Swales, 1997, p. 378). At the same time, however, the growing importance assumed by English in legal communication and the effect that the pervasive presence of English has on certain areas of law (e.g., Contract Law, see Campos, 2010), are a clear indication of a tendency which is spreading globally.

In the case of LELF, the choice of the language needs further problematization in that it inevitably highly dependent on the existing legal system. In other communicative situations, such as in BELF settings, English terminological choices often permeate the speakers' L1, thus facilitating the creation of a common background; instead, the specific terminology of the law and the lack of equivalent terms in other languages or legal systems lead to further discursive complexification.

There have been questionable hypotheses that the growing usage of ELF in certain settings is due to the demand for a neutral means of communication. However, the 'neutrality' of a lingua franca is a concept that is subject to criticism in that any language choice does not only have specific social implications but is de facto a political choice. It is also an individual choice which projects the chosen identities of its users as with any other kind of language use (Baker, 2015; Baker \& Jenkins, 2015).

The ostensibly neutral nature of English is at odds with the impossibility of applying some specific concepts without laborious interpretative efforts when dealing with a different system, especially outside Common Law countries. Notions such as equity or tort, inter alia, necessarily entail sophisticated hermeneutical efforts and a deep knowledge of different systems in order to be adequately employed without running into simplifications and inaccuracies. In this respect, Orts Llopis aptly remarks: "cultural and epistemological variances shape legal traditions and, hence, the peculiar traits of their legal texts and their interpretive techniques" $(2015, \mathrm{p}$. 25). What is more, the global use of English in legal contexts has also occasionally resulted in a partial distortion of concepts coming from the Anglo-Saxon substantive law when adopted by other systems (Audit, 2001; Orts Llopis, 2015).

\subsection{The Nature of BELF and LELF}

Although different in many respects (e.g., professional contexts of usage, types of users, heterogeneity of 
domains, etc.), BELF and LELF do share some important traits whose delineation may be used as an aid when considering a formal conceptualization of LELF. Drawing on Kankaanranta and Planken (2010), Liu and Liu (2017), and Kankaanranta and Louhiala-Salminen (2018), we can identify some of the main features of BELF, namely: (a) an emphasis on directness and clarity, rather than on accuracy, in terms of pronunciation; (b) the use of technical vocabulary; (c) the presence of specific genres with precise conventions; and (d) the tendency to move beyond factual explanations in order to focus on building rapports and relationships. To some extent, these categories may also be applied to LELF. In particular, the presence of technical vocabulary and lexical precision (which in itself is a defining feature of the law), and the existence of specific legal genres, which develop not only within consolidated rhetorical conventions but also according to specific legal constraints, generally characterize LELF textual productions as well. Moreover, the analysis of BELF, and more specifically of spoken communication in business contexts, demonstrates the emergence of pragmatic and metapragmatic devices (e.g., repetition, repair, or backchanneling), which also pertain to LELF (Author, forth.).

Another feature which BELF and LELF share is their use within a specific community of practice, whose members draw on a shared repertoire which is developed jointly, according to their competences, in order to adapt to specific purposes (Wenger, 1998, p. 82). Thus, the members themselves contribute to the creation of dynamic situational resources. Although legal language is commonly seen as a prerogative of legal professionals, the literature has often pointed out that laypeople are inexorably important actors in legal communication processes, given the general applicability of the law itself. In particular, LELF develops among, and thanks to, speakers with different language backgrounds and levels of English proficiency, but also belonging to different cultures and, more specifically, different legal cultures.

From a social-constructionist approach to professional practice, identities (and, notably, professional identities) are seen as dynamic, non-essentialist entities. They are co-constructed in interaction as "in communication actors co-create their subjectivities in the form of personal and professional identities, relationships, communities and cultures through linguistic performances" (Jian, Schmisseurs, \& Fairhurst, 2008, p. 314). It is a truism that people do not interact in a cultural vacuum and that their own personal, professional, and legal cultures shape every communicative event. Consequently, communication, especially in LELF, is based on the complex coexistence and mutual influence of three levels: the micro level, namely the situated communicative event; the meso level, i.e., the specific institutional or organizational context; and the macro level, which refers broadly to the legal, social, political, economic, and cultural context. A clear demarcation between these interconnected planes is often impossible, given their inherent interdependence. However, they constitute analytical categories which are functional to any investigation of authentic LELF settings.

\section{LELF: Perceptions, Concerns and Affordances}

The affirmation of consolidated practices which are based on the usage of LELF may be considered as an essential feature of contemporary legal communication at an international level. Indeed, such discursive practices allow for the overcoming of linguistic barriers in a wide range of legal settings.

However, the use of English as a lingua franca has often been perceived not as a means of communication which may favor intercultural exchange, but rather as an imposition which may, as a consequence, marginalize local cultures and tongues (Canagarajah, 1999; Gotti, 2012). The field of law has been no exception to this phenomenon with the affirmation of English in international legal communication. Although deemed necessary from a practical standpoint, the widespread use of English in the field of law is at times seen as the expression of an Anglocentric perspective which contrasts with the specificity of a given legal culture and legal system. This is particularly relevant as many areas of the law are considered indiscernible from the use of a national language, whose substitution with a lingua franca may lead to oversimplifications which are in stark contrast to the accuracy and the precision of the law. In this respect, the law seems to epitomize the locus of a phenomenon which is tangible in all fields, but which assumes a crucial role in legal communication. Indeed, the realization of law is based on the strong relationship between linguistic, cultural, and professional practices which exist in their reciprocal lights. Indeed, a specific legal culture inevitably affects, and is in turn affected by, given linguistic and textual realizations.

The main concerns which arise regarding the widespread use of English in international communication may be distilled into two aspects: on the one hand, the disadvantage of some users due to a lack of command of the language, and, more often, a fear of contamination by an Anglocentric perspective. In this respect, the use of a lingua franca in the field of law may be seen as problematic because of three main factors:

1) the specificity of a legal system;

2) the specificity of a legal culture; and 
3) the specificity of a community of practice and its identity traits.

Firstly, each national legal system is characterized by specific peculiarities which have evolved over time, and which find an expression in a specific language. Consequently, terminological choices made in order to refer to precise concepts which characterize a system are often untranslatable across borders, and the use of a lingua franca may alter or distort the original meaning. Secondly, even when dealing with similar legal systems, each country has given its "idiosyncratic national cultural imprint" (Bohlander, 2014, p. 493) to a certain model, thus rendering it unique. A lingua franca may not be congruent with the peculiarities of specific cultural values and conventions, as well as norms and peculiarities, dispositions, experiences, and practices. The internationalization of English in legal settings is seen as endangering cultural legal traditions through standardization and impoverishment, in that the linguistic and discursive features of English may impact the socio-pragmatic constructions of legal concepts and their related practices. Thirdly, specialists may be prone to preserve their national/local and professional identity which is also conveyed through a given language. Hence, the choice of another language may be seen as an attempt to annihilate identity differences in terms of communities of practice.

In order to achieve successful communication in international legal settings, language knowledge and disciplinary knowledge have to be accompanied by practice within a certain community and the understanding of the disciplinary culture. In this respect, Candlin, Bhatia and Jensen (2002, p. 312) argue:

"Learning to write legal discourse is part of a process of learning to participate in the affairs of the legal community and its disciplinary culture. On this argument, it is not enough to be able to construct legal sentences as part of the mastery of some specialist genres, but also to be aware of the place of such genres in the disciplinary community; in essence to ask why such genres are written the way they are. To do so is to evoke the conditions and processes of legal practice. It is exactly this mix of generic and disciplinary knowledge, which constitutes the training of legal specialists."

Thus, the use of Legal English as a Lingua Franca needs a linguistic competence which is on a par with discursive, cultural, and social competences. In particular, the notion of social competence is described by Bhatia as a multifaceted skill which "incorporates an ability to use language more widely to participate effectively in a wide variety of social and institutional contexts to give expression to one's social identity, in the context of constraining social structures and social processes" (Bhatia, 2004, p. 144).

The concern over English as a medium applies to the field of law in several other contexts as well. For instance, work produced by law academics is under relative pressure to comply with English writing. It is true that publications in a national language continue to characterize certain areas of the law (e.g., regarding domestic law), but the tendency to employ English is growing globally. As Bohlander points out, "[w]hile still useful for a domestic debate, publications in languages other than English do not stand a serious chance of being noticed and cited on the international level. If authors from non-Anglophone countries want to influence the international discussion, they will have to use the common idiom" (Bohlander, 2014, p. 513). Consequently, the widespread concern that the diffusion of the English language may lead to an affirmation of Anglophone intellectual and legal cultures over national ones does not appear to be completely without reason.

On a practical note, another issue which should be taken into account is that existing legal doctrines are not autonomous crystallized concepts, but rather they derive from a given contextual framework, and the divergent understanding of legal doctrines may even affect the very fulfilment of justice. For instance, the question of the appropriateness of the usage of English in international criminal law is extensively discussed by Bohlander (2014). The author, by means of an example, analyzes the Lubanga Trial (Note 1) judgment and shows that more than $80 \%$ of the sources used in the judgment were in English. This has crucial implications, not only in terms of the textual realization of the judgment, but also for the creation of the judgment itself, due to the implementation of specific paradigms lying behind the development of a decision.

By taking Bohlander's (2014, p. 513) reflection to a more general level, we can argue that there is a substantial risk that LELF may continue to be framed according to (and to view itself through the prism of) the English language and related cultural apparatus(es). Although such a process is to some extent inevitable, efforts should be made on the part of all subjects involved to go beyond the unproblematic acceptance of this phenomenon and to gain more awareness of its implications and consequences.

\section{Conclusions}

This paper started with the acknowledgment that, in the last few decades, the increased porousness of national barriers has contributed to the globalization of communicative practice and English has de facto become the 
privileged medium in many settings, including legal ones. Thus, the aim of the present study was to reflect upon how English as a Lingua Franca is used in different legal contexts.

The discussion of the appropriateness of the use of English requires particular attention and involves a wide range of stakeholders: legal institutions, legal professionals, politicians, semi-experts, academicians, students, training providers, textbook writers, and related professionals (legal translators, court interpreters, etc.), as well as, ultimately, every citizen given the universality of the consequences of law. In particular, the linguistic and discursive issues generated by the direct or indirect interaction between people, institutions, and organizations drawing on different legal and cultural systems, are problematic not only for language specialists, but also for legal professionals at large.

The paper argues for the necessity and the ineluctability of the diffusion of LELF across legal settings. At the same time, it stresses that significant concerns have arisen within and outside professional circles as regards the applicability of a lingua franca across (sometimes profoundly) different legal systems and cultures. For instance, a doctrinal attitude hinging on constructs which are verbally realized in a given language may suffer from the usage of a lingua franca, due to linguistic and cultural differences and divergences in terms of professional practices.

Moreover, the application of legal texts drafted in (or translated into) English has become a standard practice in several multilingual contexts. Consequently, a comprehensive and sensitive approach towards the epistemological genesis of such texts, and the related implications for the fulfilment of justice, is imperative (see Orts Llopis, 2015). Discourse in law is thus a question of ideology, power, and practice, and not merely of linguistic didactics. Indeed, the law is not only expressed through language, but it is realized through indissoluble links between language, discursive practices, and disciplinary knowledge. Effective communication in international legal contexts inevitably requires adequate language skills, as well as profound knowledge of the legal cultures involved and the legal systems in which they are enshrined.

The observations made in this study only represent a preliminary step for a deeper understanding of the characteristics of Legal English across communities and for a conceptualization of LELF. A pressing problem that we are facing is related to the substantiation of the complex relationship between the theoretical acceptance of LELF and the empirical observation of the discursive construction of LELF events, which represent complex and multifaceted loci of analysis. Thus, further studies should take into account a wider range of communicative events taking place in different legal settings in order to test the reflections offered. Future research in this field can deepen the discussion of the characteristics and the specificities of LELF, as well as its evolution. Indeed, legal discourse is often labelled as the static and conservative form of discourse by antonomasia. Conversely, discursive practices are in a constant state of flux, especially when Legal English is used as a lingua franca.

\section{References}

Audit, B. (2001). L'américanisation du droit: Introduction. Archives de philosophie du droit, 45, 7-11.

Baker, W. (2015). Culture and Identity through English as a Lingua Franca. Rethinking Concepts and Goals in Intercultural Communication. Berlin, Boston: De Gruyter Mouton. https://doi.org/10.1515/9781501502149

Baker, W., \& Jenkins, J. (2015). Criticising ELF for a Response to Recent Criticism. Journal of English as a Lingua Franca, 4(1), 191-198. https://doi.org/10.1515/jelf-2015-0013

Bhatia, V. K. (2004). Worlds of Written Discourse: A Genre-Based View. London: Continuum.

Bhatia, V. K., Engberg, J., Gotti, M., \& Heller, D. (Eds.) (2005). Vagueness in Normative Texts. Bern: Peter Lang.

Boele-Woelki, K. (2010). Unifying and Harmonizing Substantive Law and the Role of Conflict of Laws. The Hague: The Hague Academy of International Law. https://doi.org/10.1163/9789004249950

Bohlander. M. (2014). Language, Culture, Legal Traditions, and International Criminal Justice. Journal of International Criminal Justice, 12(3), 491-513. https://doi.org/10.1093/jicj/mqu034

Campos, M. Á. (2010). Going Beyond the Obvious in English for Legal Purposes: A Few Remarks on International Legal English as a Lingua Franca in Europe. In Á. Linde López \& R. Crespo Jiménez (Eds.), Professional English in the European Context: The EHEA Challenge (pp. 175-194). Bern: Peter Lang.

Canagarajah, C. (2013). Translingual Practice: Global Englishes and Cosmopolitan Relations. London: Routledge. https://doi.org/10.4324/9780203120293

Canagarajah, S. (1999). Resisting Linguistic Imperialism in English Teaching. Oxford: Oxford University Press. 
Candlin, C. N., Bhatia, V. K., \& Jensen, C. (2002). Developing Legal Writing Materials for English Second Language Learners: Problems and Perspectives. English for Specific Purposes, 21, 299-320. https://doi.org/10.1016/S0889-4906(01)00029-1

Cogo, A. (2016a). Conceptualizing ELF as a Translanguaging Phenomenon: Covert and Overt Resources in a Transnational Workplace. Waseda Working Papers in ELF, 5, 1-17.

Cogo, A. (2016b). Visibility and Absence: Ideologies of 'Diversity' in BELF. In M. Pitzl \& R. Osimk-Teasdale (Eds.), English as a Lingua Franca: Perspectives and Prospects. Contributions in Honour of Barbara Seidlhofer (pp. 39-48). Berlin: De Gruyter Mouton.

Cogo, A., \& Yanaprasart, P. (2018). "English is the Language of Business": An Exploration of Language Ideologies in Two European Corporate Contexts. In T. Sherman \& J. Nekvapil (Eds.), English in Business and Commerce: Interactions and Policies (pp. 96-116). Berlin: De Gruyter. https://doi.org/10.1515/9781501506833-005

Crettez, B., Deffains, B., \& Musy O. (2013). On the dynamics of legal convergence. Public Choice, 156(1-2), 345-356. https://doi.org/10.1007/s11127-011-9907-7

Ehrenreich, S. (2016). English as a Lingua Franca (ELF) in International Business Contexts: Key Issues and Future Perspectives. In K. Murata (Ed.), Exploring ELF in Japanese Academic and Business Contexts (pp. 135-155). London/New York: Routledge.

Frade, C. (2007). Power Dynamics and Legal English. World Englishes, 26(1), 48-61. https://doi.org/10.1111/j.1467-971X.2007.00487.x

Gerritsen, M., \& Nickerson, C. (2009). BELF: Business English as a Lingua Franca. In F. Bargiela-Chiappini (Ed.), The Handbook of Business Discourse (pp. 180-192). Edinburgh: Edinburgh University Press.

Gotti, M. (2012). Cross-cultural Aspects of Academic Discourse. Brno Studies in English, 38(2), 59-78. https://doi.org/10.5817/BSE2012-2-4

Higgs, R. (2000). Regulatory Harmonization: Sweet-sounding, Dangerous Development. The Independent Review, 4(3), 467-474.

Jenkins, J. (2015). Repositioning English and Multilingualism in English as a Lingua Franca. Englishes in Practice, 2(3), 49-85. https://doi.org/10.1515/eip-2015-0003

Jian, G., Schmisseurs, A., \& Fairhurst, G. (2008). Organizational Discourse and Communication: The Progeny of Proteus. Discourse and Communication, 2(3), 299-320. https://doi.org/10.1177/1750481308091912

Kankaanranta, A., \& Louhiala-Salminen, L. (2018). ELF in the Domain of Business-BELF What does the B Stand for? In J. Jenkins, W. Baker \& M. Dewey (Eds.), Routledge Handbook of English as a Lingua Franca (pp. 309-320). London: Routledge. https://doi.org/10.4324/9781315717173-26

Kankaanranta, A., \& Planken, B. (2010). Belf Competence as Business Knowledge of Internationally Operating Business Professionals. Journal of Business Communication, 47(4), 380-407. https://doi.org/10.1177/0021943610377301

Lierman, S. (2013). Law as a Complex Adaptive System: The Importance of Convergence in a Multi - layered Legal Order. Ius Commune Conference, Maastricht, 28 November 2013, 1-15. https://doi.org/10.1016/j.pragma.2016.10.006

Liu, P., \& Liu, H. (2017). Creating Common Ground: The Role of Metapragmatic Expressions in BELF Meeting Interactions. Journal of Pragmatics, 107, 1-15.

Ortega. L. (2013). Ways Forward for a Bi/multilingual Turn in SLA. In S. May (Ed.), The Multilingual Turn: Implications for SLA, TESOL, and Bilingual Education. London: Routledge.

Orts Llopis, M. Á. (2009). Legal Genres in English and Spanish: Some Attempts of Analysis. Ibérica, 18, 109130.

Orts Llopis, M. Á. (2015). Legal English And Legal Spanish: The Role of Culture and Knowledge in the Creation and Interpretation of Legal Texts. ESP Today, 3(1), 25-43.

Seidlhofer, B. (2011). Understanding English as a Lingua Franca. Oxford: Oxford University Press.

Swales, J. (1997). English as Tyrannosaurus Rex. World Englishes, 16(3), 373-382. https://doi.org/10.1111/1467-971X.00071 
Vogt, N. (2004). Anglo-internationalisation of Law and Language: English as the Language of the Law? International Legal Practitioner, 29, 13-17.

Wenger, E. (1998). Communities of Practice: Learning, Meaning, and Identity. Cambridge: Cambridge University Press. https://doi.org/10.1017/CBO9780511803932

\section{Note}

Note 1. The Prosecutor v. Thomas Lubanga Dyilo. The trial was held at the International Criminal Court in The Hague (2009-2012). Lubanga was a war criminal from the Democratic Republic of the Congo and in 2012 he was sentenced to 14 years of imprisonment by the ICC. Judgement available at: https://www.icc-cpi.int/pages/record.aspx?uri=1379838 (accessed January 08, 2019).

\section{Copyrights}

Copyright for this article is retained by the author, with first publication rights granted to the journal.

This is an open-access article distributed under the terms and conditions of the Creative Commons Attribution license (http://creativecommons.org/licenses/by/4.0/). 